\title{
Movimento populacional e transformações locais: os motores da
} Itaipu Binacional

Resumo: A colonização do Oeste do Paraná foi protagonizada por três segmentos distintos, mas complementares: a ocupação estrangeira, com o modelo obrageiro, as grandes colonizadoras, que possibilitaram o inicio efetivo do processo de colonização, e o Estado, que através de suas ações é o regente dos segmentos anteriores. Além da análise desses atores, aborda-se o crescimento e a retração populacional influenciada pela construção da Usina Hidrelétrica Binacional Itaipu, que cria um movimento de fluxo duplo, pois ao mesmo tempo em que atrai Imigrantes, com a oferta de emprego, expulsa o habitante com as desapropriações de terras para a formação do reservatório. As considerações e conclusões do artigo respaldam-se em autores proeminentes na temática, bem como no Instituto Brasileiro de Geografia e Estatística (IBGE) e o Instituto Paranaense de Desenvolvimento Econômico e Social - (IPARDES).

\section{Population movement and local transformations: Itaipu Binacional's engines}

\footnotetext{
Abstract: Distinct but complementary segments played role in the colonization of the West of Paraná: foreign occupation, with the obrageiro model, the colonizing, that made possible the effective beginning of the colonization, the construction of the Binacional Itaipu Dam, and the State, that through its actions is the regent of the previous segments. Besides the analysis of those factors, it discussed, in the article, the growth and population retraction influenced by the construction of the dam, that creates a movement of double flow, at the same time in that it attracts migrants, with the job offer, it expels the inhabitant with the expropriation of lands for the formation of the reservoir. The considerations and conclusions are backed by prominent authors in the theme, in the Brazilian Institute of Geography and Statistics (IBGE) and the Parana Institute of Economical and Social Development - (IPARDES).
}

* Professor na Universidade Tecnológica Federal do Paraná (UTFPR). Doutor em Geografia pela Universidade Estadual de Maringá (UEM).

\section{Palavras-chave:}

Oeste do Paraná, colonização, Itaipu, mobilidade.

\section{Key-Words:}

West of Paraná, colonization, Itaipu, mobility. 


\section{Introdução}

As influências socioambientais, econômicas, politicas, estratégicas e energéticas que a Usina Hidrelétrica Binacional de Itaipu exerce na região Oeste do Paraná, no Brasil e no Paraguai são notáveis e mutáveis. Para este artigo delimitar-se-á a dimensão populacional, pois considera-se que a mobilidade deste espaço foi influenciável pela 'fase' em que se encontrava o desenvolvimento deste empreendimento multinacional de geração energética.

Neste artigo apresenta-se a mobilidade populacional que a região Oeste do Estado do Paraná (Figura 1), passou durante o processo de ocupação gerenciada pelas obrages argentinas e paraguaias, no período da colonização oficial. Caracterizado pela concessão de terras, as grandes empresas colonizadoras e as contribuições que a construção da hidrelétrica binacional de Itaipu teve na alteração territorial desse espaço com a mobilidade populacional instaurada.

São dinâmicas que ditam um fluxo constante de ocupação e desocupação territorial, com a atração de migrantes que buscavam terras baratas para a subsistência, seguidos de pessoas que afluem ao município de Foz do Iguaçu empregando-se na construção da usina e, posteriormente, o desalojamento dos primeiros, com a desapropriação de terras circunvizinhas para a formação do lago.

Figura 1 - Mesorregião Oeste do Estado do Paraná.

Geografia Ensino \& Pesquisa, v. 18, n. 2 p. $7-24$, maio/ago. 2014

Movimento populacional e transformações locais: os motores da Itaipu binacional

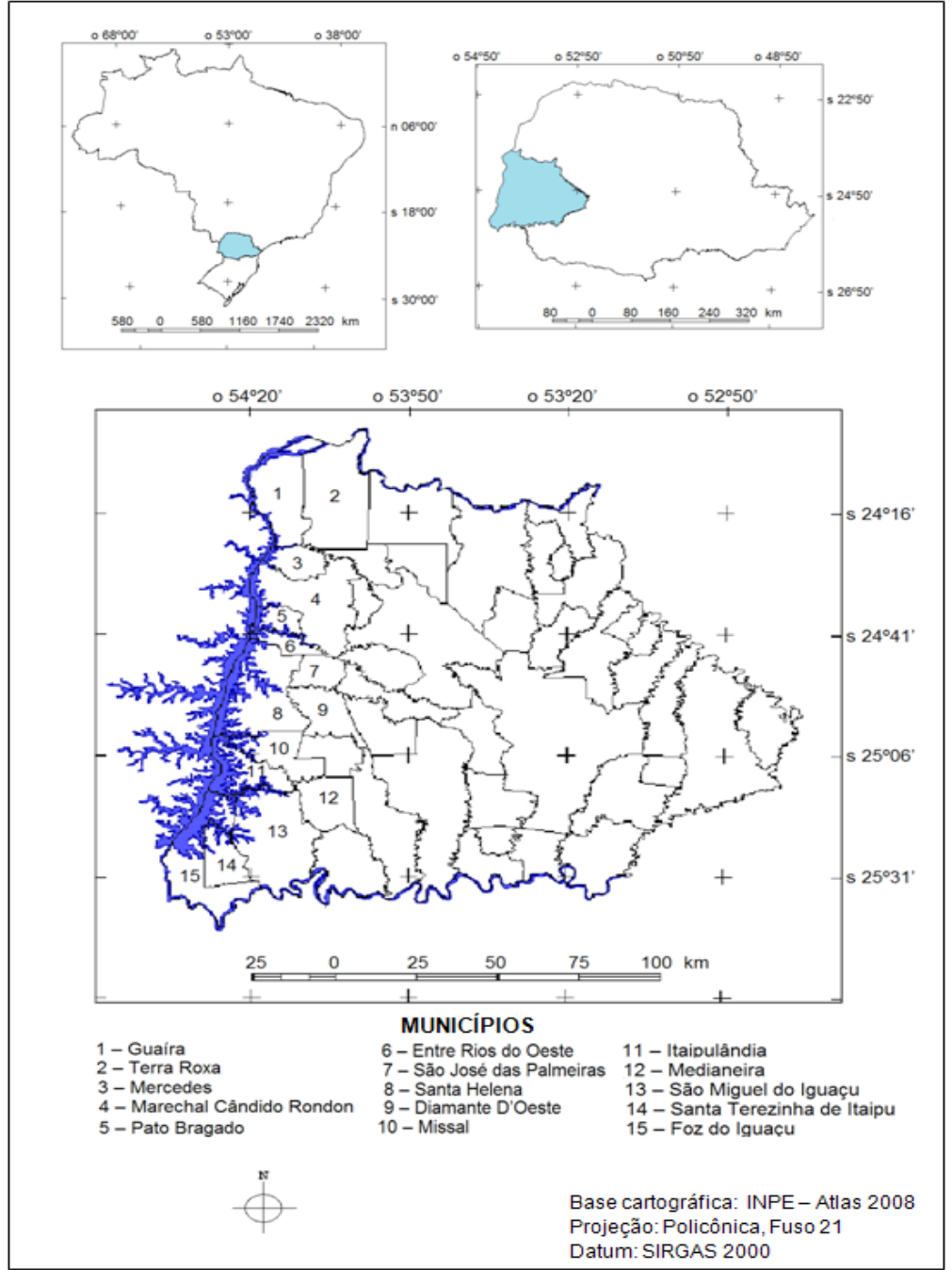

Fonte: elaborado pelo autor. 
Destaca-se que o conceito de região adotado tem como fundamento Haesbaert (2004), que marca a sua trajetória como polissêmico. Pois começa pelo seu uso em vários domínios: no senso comum, na administração pública e no campo das ciências. No senso comum relaciona região com a localização e a extensão de certo fato ou fenômeno, sem critérios definidos, precisão ou escala espacial. Já a noção de unidade administrativa está relacionada com a divisão regional na qual o poder público exerce hierarquia, controle e instrumento de ação. E no campo das ciências está associada a uma área sob certo domínio caracterizado por uma regularidade de propriedade que a definem.

Diante desta polissemia o artigo transitará por estes domínios de senso comum, unidade administrativa e no campo da ciência, sem a preocupação de demarca-los no decorrer do texto.

Para entender a complexa dinâmica adotou-se a estratégia de uma inserção breve nos três processos principais que a região é sujeita no decorrer de sua história: o Complexo Obrageiro, a Ação Estatal e a Iniciativa Privada através das colonizadoras e do colono.

Esta análise é embasada nas reflexões de autores como Rubem Murilo Leão Rego (1975), Ruy Christovan Wachowich (1982), Cecília Maria Westphalen (1968), Ivone Carletto Lima (2004), Milton Santos (1996 e 2011) entre outros, bem como, pelos dados do Instituto Brasileiro de Geografia e Estatística e do Instituto Paranaense de Desenvolvimento Social e Econômico comprova-se a mobilidade populacional.

\section{O complexo obrageiro: uma ocupação estrangeira no Brasil.}

As concessões de terras a empresas, principalmente de capital argentino e inglês, originou a exploração econômica conhecida como complexo Obrageiro, que extraia a madeira e a erva-mate da região Oeste do Paraná, atendendo/suprindo com esta matéria-prima o mercado crescente, em especial, o inglês. Tratava-se de um sistema de exploração e predação dos recursos naturais realizado desde as últimas décadas do século XIX até a década de 1930 no século XX.

Porém, esta exploração não promoveu uma ocupação efetiva do território, mas, somente, uma exploração econômica. Como apresenta Lima (2004, p. 108):

\footnotetext{
[...] as Obrages, se constituíam em grandes empresas agrárias que designavam um latifúndio. Não havia interesse em promover o povoamento da região por parte dos obrageiros, mas retirar as riquezas que lhes pudessem prover lucros imediatos. A erva-mate e a madeira respondiam a esse requisito e se transformavam nos principais produtos do contrabando, na hoje chamada, 'três fronteiras'.
}

Este modelo de exploração "primava por um tipo de ocupação extensiva, rarefeita, isto facilitado pela concessão de grandes tratos de terras devolutas, pelo Governo do Estado, onde o 'arrendatário' tinha como principal objetivo à exploração do mate e da madeira”. (WESTPHALEN, 1968, p. 2)

Desta forma a Obrage baseou-se, como já mencionado, no binômio mate-madeira, constituindo-se em uma exploração típica das regiões cobertas pela mata subtropical, em território argentino e paraguaio. Portanto, foram os Obrageiros argentinos os principais responsáveis pela introdução desse sistema de exploração econômica em território brasileiro, mais especificamente em áreas paranaense e sul mato-grossense, sendo o rio Paraná a via natural de escoamento do produto extraído nessa região.

Esta frente extrativista de origem Argentina penetra através do rio Paraná, nos territórios do Oeste do Estado do Paraná. Contudo:

[...] a existência das corredeiras de Sete Quedas dificultava a comunicação, mas serviu de proteção e isolamento para a atuação dos obrageiros. As companhias rioplatinenses fundaram inúmeros portos, entre os quais, os de Foz do Iguaçu, de Santa Helena, de Porto Britânia, de Porto Medes e de Guaíra. (LIMA, 2004, p. 109).

Geografia Ensino \& Pesquisa, v. 18, n. 2 p. 07-24, maio/ago. 2014.

Ostrovski, D

ISSN 2236-4994 
Somente em 1881 foram detectadas, pelo governo brasileiro, as primeiras penetrações dessa frente estrangeira no Oeste do Paraná. Como resposta, "em 1889 foi fundada a Colônia Militar na foz do rio Iguaçu" (LIMA, 2004, p.109), na região de fronteira, confluência entre Argentina, Paraguai e Brasil, no território brasileiro.

Paralelamente a essa Colônia Militar, o governo criou colônias no "atual município de Palmas (colônia Xopim, 1882)" (BERNARDES, 1952, p. 441), com o objetivo de ocupar e proteger este espaço territorial, que era considerado um sertão desabitado, uma vez que o núcleo populacional mais próximo das margens do rio Paraná, reconhecido pelo governo, era a fazenda do Chagu, situada a oeste do município de Guarapuava, distante trezentos quilômetros do marco fronteiriço.

A estratégia obrageira de exploração econômica não supriu as necessidades dos Governos Federal e Estadual, que além da esperada obtenção de rendimentos/lucro, deveria promover uma ocupação territorial. Ao contrário do que era esperado, o padrão obrageiro instituído causou um problema de ordem nacional, ferindo a soberania brasileira e diminuindo a figura do Estado, isto porque, as leis ali regidas provinham da Argentina e Paraguai, a moeda procedente da proveniente da Argentina e a língua falada o Castelhano.

Tentando-se inibir esta expansão estrangeira em território nacional, "em 1913 foi criada a Repartição do Serviço Fiscal Estadual pelo Estado do Paraná" com o objetivo de colonizar e apossar-se deste espaço (LIMA, 2004, p.109). No entanto, somente com a chegada da Coluna Prestes, que se fez presente na região nos anos de 1924 e 1925, as obrages perderam força e abriram espaço para que em 1930 o governo federal adotasse medidas para "nacionalizar" a região. Para isto:

[...] foi criado o território do Iguaçu, ficando como interventor responsável no Paraná, o General Mario Tourinho, que passou a tomar providências a respeito. A desarticulação das obrages e o incentivo à colonização por parte do governo atraíram a visita de Companhias Colonizadoras, principalmente vindos do Sul do país. (LIMA, 2004, p.110).

Percebe-se que o processo de colonização e ocupação deste espaço do território nacional envolveu o Estado. Segundo RAFFESTIN (1993) “o Estado está sempre organizando o território nacional por intermédio de novos recortes, de novas implantações e de novas ligações". p.152.

São concessões e acordos; que beneficiam as Empresas de Colonização, que por sua vez atraem os Colonos e/ou Pioneiros, que passam a ocupar e a explorar economicamente o território. Esta tríade é responsável pelo processo que transformou a realidade regional de um espaço geográfico desabitado para uma região amplamente incorporada ao mercado regional, nacional e mundial.

\section{A ação estatal para efetivar a colonização do Oeste do Estado do Paraná}

Mesmo com a presença das colônias militares, o governo foi forçado a tomar novas medidas para que a ocupação e colonização do Oeste do Estado do Paraná se efetivasse, já que este território possuía um sistema de extrativismo amplamente estruturado, o que criava

Geografia Ensino \& Pesquisa, v. 18, n. 2 p. $7-24$, maio/ago. 2014

Movimento populacional e transformações locais: os motores da Itaipu binacional inúmeras vantagens para que o colono envolvido com esta atividade extratora mantivesse seu estilo de produção.

Desta forma, a Colônia Militar sua respectiva população agrícola visava alterar os costumes exploratórios da região. Entretanto, isto não ocorreu nos primeiros anos. Os colonos, de modo geral, pela facilidade e lucro rápido, passaram a cortar e vender a madeira e o mate existente em seu lote. 
Para romper este ciclo de exploração, uma das medidas tomadas pelo governo foi à construção da estrada federal que corta o Estado do Paraná, hoje conhecida como BR 277, para facilitar o acesso a esse território. Conforme Nicholls (1971, p. 40), “[...] a recente finalização (em 1969) da estrada federal asfaltada desde Paranaguá e Curitiba (passando por Ponta Grossa, Guarapuava e Laranjeiras do Sul), até Foz do Iguaçu e Assunção [...] torna o futuro promissor".

A construção da BR 277 se tornou fundamental para a colonização do Oeste paranaense. Mas, essa colonização se processou seguindo três vias principais:

a) a estrada que saindo de Ponta Grossa atinge Guarapuava e vai ter a Foz do Iguaçu; b) a estrada que de União da Vitória vai ter a Palmas, segue depois para Clevelândia, ramifica-se na zona de Pato Branco e continua para Barracão, na fronteira Argentina; c) o terceiro é constituído pela estrada de Guarapuava a Campo Mourão. (BERNARDES, 1952, p. 443).

No decorrer da década de 1940 implantou-se o programa do governo federal conhecido como a Marcha para o Oeste, que entre outras medidas, procurava retomar as terras e lutar contra grileiros que, na época, detinham a posse de aproximadamente $59 \mathrm{~km} 2$ de terras paranaenses, o que representava mais de $1 / 4$ do território. Nessa intenção, o programa governamental objetivava "reconquistar milhões de hectares que deveriam ser efetivamente colonizados." (WESTPHALEN, 1968, p. 6).

Este projeto nacionalista do Presidente Getúlio Vargas buscava a construção e a concretização da faixa de fronteira, para consolidar a segurança do território. Para tal, a política nacional era a formulação de orientações para conduzir a concessão de terras, para o povoamento efetivo dessa região fronteiriça. Como relata Rego:

[...] em face da vastidão do território brasileiro não ocupado, o Brasil era visto como 'um país de imigração'. [...] Essa política de povoamento assim se define: 'As terras devolutas pertencem aos Estados, e a estes cabe fornecê-las, para serem loteadas, divididas, povoadas e trabalhadas pelos agricultores (...). Tal colonização também terá uma orientação técnica, tanto para a escolha das terras, como para a instalação dos colonos. Fundar-se-ão núcleos agrícolas, servidos de escolas rurais e aprendizados, onde os filhos dos colonos recebam instrução e conhecimentos de lavoura (...). Aproveitaremos, para isso, as terras devolutas e as distribuiremos, gratuitamente entre os colonos, fornecendo-lhes, ainda, instrumentos agrários e sementes. (REGO, 1980, p.190).

Outra medida importante, tomada pelo governo federal em relação à colonização do Oeste paranaense, foi à proibição, [...] "à propriedade da terra, por estrangeiros; nas zonas de fronteiras, sendo, em consequência, nacionalizadas várias companhias", no período de 1939 -1945, alegando motivos de segurança nacional. (WESTPHALEN, 1968, p. 6).

O Estado, como grande interventor, permaneceu a agir no decorrer dos anos, redistribuindo essas terras a novas companhias colonizadoras, que passaram a preparar o espaço para a efetiva integração ao mercado. Devido as sequentes intervenções, podemos destacar o papel do Estado como presente nos processos motivadores dos outros dois grupos que figuram no cenário regional: a empresa colonizadora e o colono; como nos coloca Westphalen (1968, p.67):

[...] na década de 40 a colonização consegue ultrapassar o Rio Iguaçu, entrando no Oeste paranaense, ao longo do Rio Paraná, até encontrar, na altura de Campo Mourão, as frentes pioneiras dos agricultores da agricultura tropical, provenientes da área paulista que, inversamente, vinham de Norte para Sul, em busca de terras para o café.

Geografia Ensino \& Pesquisa, v. 18, n. 2 p. 07-24, maio/ago. 2014.

Ostrovski, D.

ISSN 2236-4994 
Destacasse que a frente pioneira do Sudoeste teve sua formação motivada por um crescimento populacional significativo nos estados do Rio Grande do Sul e Santa Catarina. Podemos, então, caracterizar um extravasamento de população, o excedente populacional migrou para a região a ser colonizada. Outro fato pertinente foi uma constante divisão de terras entre herdeiros, o que gerou nos Estados citados os minifúndios, os quais já não ofereciam condições para o sustento da família que se formava, motivando, por vez, o movimento migratório dos Estados do Rio Grande do Sul e Santa Catarina para a região Oeste do Paraná. Por fim, aproveitando das iniciativas governamentais e do crescente mercado consumidor de novas terras, observa-se a significativa presença das empresas colonizadoras na área paranaense a ser colonizada, dotando este espaço de uma infraestrutura mínima para a chegada do novo colonizador.

\section{A iniciativa privada: a ação das colonizadoras}

A empresa privada, Industrial Madeireira Colonizadora do Paraná. S.A - Maripá, que desempenhou um papel fundamental na colonização do oeste, pois, através de seus "[...] fundadores e responsáveis participavam ainda, de outras companhias colonizadoras da região, tais como a Colonizadora Gaúcha Limitada (...); a Industrial Agrícola Bento Gonçalves (...); a Colonizadora Matelândia (...); a Terras e Pinhais Limitada (...); a Pinho e Terras Limitada". (WESTPHALEN, 1968, p. 21) Sendo ela (ou seus sócios) responsáveis quase que pela totalidade da disponibilidade de terras para a venda na época.

O historiador Valdir Gregory (1997) explica que estas empresas montavam seus planos de ação, preocupando-se com o elemento humano, com a pequena propriedade, com a policultura e a industrialização; selecionava agricultores que se adaptassem à região, isto porque, segundo estas empresas, era o elemento humano eurobrasileiro do sul do Brasil, ou seja, os descendentes de alemães, italianos e de outros imigrantes, que acostumados com a lida agrícola colonial da pequena propriedade, formavam o perfil adequado ao novo colonizador oestino. Assim sendo, o espaço colonizado teria sua estrutura fundiária, estradas, núcleos populacionais de acordo com a experiência do espaço colonial das antigas Colônias do Sul. Com esta organização criada pelas empresas colonizadoras:

[...] iniciava uma nova fase de povoamento, com a atuação de companhias colonizadoras particulares que provocaram a entrada de agricultores descendentes de alemães e italianos, que se instalaram na terra, produzindo cereais e criando porcos e galinhas, ou seja, uma diversidade nas atividades econômicas. (LIMA, 2004, p.112).

Assim, essas empresas responderam pela eficaz colonização, transformaram o panorama local em um "[...] eixo propulsor da repartição da terra e sua efetiva ocupação pelos proprietários privados". (WESTPHALEN, 1968, p. 21). Os proprietários, vindos de antigas regiões coloniais dos Estados do Rio Grande do Sul e Santa Catarina, eram impelidos a realizar esta migração, pois, "desde o final do século XIX, vinha acentuando-se a insuficiência de terras face aos aumentos da população de agricultores, descendentes dos imigrantes italianos e alemães". (WESTPHALEN, 1968, p. 6).

Com a inserção real do agente colonizador, tem-se um fluxo crescente de migrantes para

Geografia Ensino \& Pesquisa, v. 18, n. 2 p. $7-24$, maio/ago. 2014

Movimento populacional e transformações locais: os motores da Itaipu binacional a região Oeste do Estado do Paraná, atraídos pelas condições criadas por estas companhias: vias de acesso, construção de centros urbanos, financiamentos para compra de terras, entre outros, o que favorecia a mínima sobrevivência e prosperidade financeira.

Como pode-se observar na Tabela 1 o incremento populacional na região é significativo. Em 1950 correspondia por somente 16.421 pessoas, com uma taxa de urbanização de $20,73 \%$. Na década seguinte, de 1960, o número passa para 113.752 habitantes com a 
evolução na taxa de urbanização na ordem de 26,24\%. Mas o salto mais significativo ocorre na década de 1970, quando há a junção entre a migração sulista e o inicio da construção da hidrelétrica binacional de Itaipu.

Nessa década, a população passa de 113.752, para 763.723 habitantes, um aumento de 649.971 habitantes. Aliado ao número substancial, outro dado que chama a atenção é a taxa de urbanização, que sofre uma pequena queda de 6,29\%, passando para $19,95 \%$.

Tabela 1 - Evolução da criação de municípios no Oeste do Paraná - 1950/2007

\begin{tabular}{l|c|c|c|c|c}
\hline Censo & $\begin{array}{c}\text { Número de } \\
\text { Municípios }\end{array}$ & $\begin{array}{c}\text { População } \\
\text { Total }\end{array}$ & $\begin{array}{c}\text { População } \\
\text { Urbana }\end{array}$ & $\begin{array}{c}\text { População } \\
\text { Rural }\end{array}$ & $\begin{array}{c}\text { Grau de } \\
\text { Urbanização (\%) }\end{array}$ \\
\hline 1950 & 1 & 16.421 & 3.404 & 13.017 & 20,73 \\
1960 & 4 & 113.752 & 29.843 & 84.412 & 26,24 \\
1970 & 19 & 763.723 & 152.354 & 611.948 & 19,95 \\
1980 & 20 & 953.364 & 490.662 & 452.902 & 51,47 \\
1991 & 35 & 1.017 .300 & 738.136 & 279.164 & 72,56 \\
2000 & 49 & 1.140 .315 & 937.484 & 202.831 & 82,21 \\
2007 & 49 & 1.246 .881 & 1.060 .336 & 186.645 & 85,03 \\
\hline
\end{tabular}

Fonte: adaptado de IPARDES (2008).

Esta alta taxa de ruralização pode ser explicada pela ocupação da população ativa na década de 1970. Explica o Instituto Paranaense de Desenvolvimento Econômico e Social (IPARDES 1977, p. 76) que:

\footnotetext{
O setor primário [...] caracterizava-se principalmente por concentração da população rural com relação a total, predomínio absoluto de minifúndios, absorção da força de trabalho categorizada na classe não remunerada, voltada principalmente às culturas temporárias de soja, trigo, milho, feijão, arroz e mandioca, assim como à suinocultura. Por outro lado, nessa área, não são representativos as culturas permanentes nem seu rebanho bovino, verifica-se igualmente, a relativa inexistência de latifúndios por exploração.
}

Comprova-se tais afirmações com a análise da Tabela 2 e constatar que no Oeste paranaense o setor primário correspondia, na década de 1970 , a $86,8 \%$ da absorção da população economicamente ativa. O setor secundário a $2.2 \%$, era quase inexistente, e, por fim, o setor terciário com $11, \%$.

Tabela 2 - Evolução da criação de municípios no Oeste do Paraná - 1950/2007

\begin{tabular}{lcccc}
\hline Unidades Espaciais & Setor Primário & Setor Secundário & Setor terciário \\
\hline Oeste & $86,8 \%$ & $2,2 \%$ & $11,1 \%$ \\
Sudoeste & $89,4 \%$ & $2,1 \%$ & $8,5 \%$ \\
Estado do Paraná & $73,4 \%$ & $4,2 \%$ & $22,4 \%$ \\
\hline
\end{tabular}

Fonte: IPARDES (1977, p. 74).

O Estado e o Agente Colonizador atraíram o terceiro componente deste cenário, o colono/ Geografia Ensino \& Pesquisa, v. 18, n.2 p. 07-24, maio/ago. 2014. pioneiro, que passará a usufruir e interagir neste espaço, transformando-o, adaptando-o a sua realidade e transformando-se no sujeito desta ação. O processo de colonização, pilotado pelos agentes analisados anteriormente, completa-se com a participação dos sujeitos, ou seja, dos colonos.

Ostrovski, D. 


\section{Colonos: os sujeitos da ação colonizadora}

O colono é a principal peça da engrenagem em um processo de ocupação/colonização regional ou frente pioneira. Como afirma Bernardes (1952, p. 439), surge como "[...] um novo tipo social, que empreende uma tarefa até então negligenciada: abater a mata virgem, cultivar grandes áreas contíguas e expandir-se cada vez mais para o interior, em direção ao oeste".

É a peça que move a máquina colonizadora, justificando a presença do colonizador bem como a criação de uma zona de atração, será o comprador das terras na nova frente pioneira. Ressaltamos que seu trabalho atende ao objetivo governamental, que é a inserção por meio da relação trabalho e produção, da região no contexto socioeconômico do Estado, que cria a verdadeira integração espacial.

Esse colono/pioneiro que chegava a região poderia comprar mais de um lote oferecido pelas empresas colonizadoras, mas a escassez de recursos para a compra dificultou a formação de grandes propriedades. Constitui-se um conjunto amplo e engrenado, onde a empresa oferece serviços e a terra e o colono paga por este benefício. Constitui-se, assim, um espaço de pequenas propriedades, caracterizado pelo minifúndio. Como nos aponta o IPARDES $(1977$, p. 77 ) sobre a realidade do Oeste na década de 1970.

[...] considerando-se as unidades que possuem até 50 ha, o número de estabelecimentos alcança 95,24\% do total de estabelecimentos [...]. Caso se tome as propriedades de até $10 \mathrm{ha}$, mesmo assim, o número de estabelecimentos corresponde a $50,72 \%$.

Mesmo com a predominância das pequenas propriedades, com cerca de quatro (4) alqueires paulistas $\left(24.200 \mathrm{~m}^{2}\right)$, o pagamento, em muitos casos, não era à vista. Sendo assim, era consolidado o contrato de compra e venda da terra, dava-se a posse temporária ao colono, e somente ao findar das prestações, concedia-se o título de domínio pleno do imóvel. O conjunto se completa e a região é efetivamente colonizada e integrada ao cenário Estadual e Nacional. Mas, nesse contexto, cria-se

\footnotetext{
[...] a terra, como objeto de propriedade ou de posse, tem sua relevância determinada, no processo de expansão do capitalismo, pelo menos sob duas formas: como meio de produção e como objeto de especulação imobiliária. No quadro dos processos aqui estudados, sob a primeira forma ela se constitui no meio de produção fundamental que garante a reprodução da agricultura camponesa, principalmente nas condições de realização da frente de expansão. A luta que o pequeno produtor desenvolve tem como objetivo principal (...) a transformação da posse de um pedaço de terra em propriedade privada e meio individual de produção. Por outro lado, sob a segunda forma, os objetivos de se garantir o domínio ou a apropriação privada da terra se concretizam no interesse de apropriação de lucros decorrentes do processo de sua mercantilização, pura e simples. (REGO, 1980, p. 193).
}

Neste contexto, pode-se classificar o colono/pioneiro como o sujeito da ação. Sua presença justifica a existência da colonizadora e viabiliza a ocupação almejada pelo Estado brasileiro. Ocupa-se uma área e integra-se ao setor econômico do país.

Geografia Ensino \& Pesquisa, v. 18, n. 2 p. $7-24$, maio/ago. 2014

Movimento populacional e transformações locais: os motores da Itaipu binacional

\section{Economia Regional: do modelo obrageiro a construção da hidrelétrica binacional de Itaipu}

Lembra-se que o processo de colonização passou por transformações, transcorrendo 
do modelo Obrageiro (mera exploração dos recursos naturais) e o processo de colonização realizado pelas companhias privadas que inseriram definitivamente a região no mapa econômico estadual.

Todavia as grandes concessões de terras para as colonizadoras se vinculavam à colonização do sertão, mas esses acordos nem sempre cumpridos, geravam esforços que eram “[...] empenhados por algumas concessionárias apenas na exploração de erva-mate e da madeira. Muitas, nem sequer iniciaram quaisquer trabalhos de ocupação efetiva da terra." (WESTPHALEN, 1968, p. 14). Com isto, a economia no início do desbravamento da região empreendeu um ritmo avassalador de exploração/extração vegetal, “[...] sendo que alguns anos de atividade dos concessionários foram suficientes para uma devastação quase completa de tudo o que pudesse representar algum valor econômico nas matas regionais". (SERRA, 1992, p. 89).

O IPARDES, (1977, p. 107), analisa que "[...] as atividades de transformação se mantiveram praticamente concentradas na indústria madeireira até meados da década de 60 ". É quando surge a figura do caboclo ou caipira, que desenvolve uma atividade basicamente de sobrevivência, tendo sua cultura principal voltada à produção de suínos. Esse cabocla/caipiras, por se dedicarem a produção para o autoconsumo, mantinham "[...] laços frouxos com o mercado e que, como estereótipo, eram conhecidos por serem preguiçosos e sem ambição, apenas interessados na mera sobrevivência, sem estarem dispostos a qualquer esforço suplementar". (GUILHERME VELHO, 1979, p. 116).

A inexpressiva participação desse grupo na economia local/regional em função da maneira de como conduzia a exploração agropastoril, conduziu uma forma bastante particular de comercialização da produção. Assim:

\footnotetext{
[...] primitivismo da cultura e da economia cabocla ia da criação à comercialização dos suínos. Quem possuía $500 \$ 000$ a um conto de réis, saia pelas picadas do sertão comprando porcos dos caboclos posseiros. Este era o safrista. Não comprava porcos por quilo e sim por centímetro, por metro, na vara ou ainda no barbante. Estas eram as expressões utilizadas para determinar a altura do animal. Na saída do mangueirão, era feito um buraco. Neste local, eram fixados duas estacas, uma de cada lado. Media-se nas estacas a altura desejada pelo comprador (safrista) geralmente de 50 centímetros. $\mathrm{O}$ travessão entre as duas partes era a vara, barbante ou arame, se o porco ao passar não alcançasse com seu dorso a vara colocada a 50 centímetros, era refugado. (WACHOWICZ, 1985, p. 90).
}

No transcorrer desse processo de colonização/exploração econômica da região, chegase a década de 1940, período que ocorre o verdadeiro input de colonização do Oeste do Paraná, efetivada pelos colonos do Rio Grande do Sul e Santa Catarina, que desenvolvem, conforme Serra, (1992, p. 73) formas de exploração diferenciadas. Observa-se “[...] uma intensiva exploração da terra, com técnicas de cultivo adiantadas para a época, e criações de porcos e de outros pequenos animais presos em cercados", mas, em contrapontos, vê-se "[...] o caboclo explorando extensivamente sua propriedade com criações de suínos a solta".

Contudo, este espaço passa por uma transformação rápida e progressiva, “[...] a partir de 1950, inicia-se a diversificação da agricultura paranaense, com o plantio, em escala comercial, do algodão, milho, feijão, arroz, cana-de-açúcar, amendoim, rami, fumo, hortelã e soja, marcando o progresso na região". (KONZEN, 1990, p. 161).

E esta tendência é comprovada pelo IPARDES, (2008, p. 31), que afirma:

Em dez anos, de 1960 a 1970, um milhão de hectares foram ocupados por novos estabelecimentos rurais, alcançando o total de 1,5 milhão de hectares. A área utilizada para o cultivo de lavouras temporárias passou de 11,8 mil para 599 mil hectares. O cultivo de soja, que não teve registro no Censo Agropecuário de 1960, ocupava 155 mil hectares em 1970. A partir daí, os dados dos Censos Agropecuários seguintes evidenciam que o comportamento da variável Lavoura Temporária deve-se basicamente

Geografia Ensino \& Pesquisa, v. 18, n. 2 p. 07-24, maio/ago. 2014.

Ostrovski, D.

ISSN 2236-4994 
às variações da área cultivada com soja. De 1970 a 1975, época do maior incremento, a área de soja cresceu em números absolutos 427 mil hectares, enquanto a área com todas as lavouras temporárias (inclusive a soja) cresceu 418 mil hectares. Ou seja, todo o acréscimo na área de lavouras temporárias decorreu do aumento da área de soja. Nos períodos seguintes, ampliações de área cultivada com lavouras temporárias foram bem menores.

A transformação, iniciada neste período, perdura até os dias atuais, com influências, locais, regionais e internacionais, como qualquer espaço envolvido em um processo de produção que necessita, para sua sobrevivência, atender a um determinado mercado. Fato claramente exemplificado por Konzen (1990, p.156)

No Paraná, o processo de transformação da agricultura seguiu tendências semelhantes às que marcaram a transformação da agricultura brasileira, e algumas regiões são caracterizadas por um desenvolvimento tecnológico mais intenso, enquanto outras permanecem com formas parcialmente tradicionais de cultivo e comercialização. A pequena exploração agrícola, quando inserida no contexto das políticas de modernização, deixou, em muitos casos, de produzir sua subsistência e o abastecimento interno, para se dedicar, ao lado das grandes, à cultura de exportação. Quando não respondeu ao apoio subsidiado de produção de exportáveis, raramente conseguiu gerar excedentes de alimentos que permitissem o aumento de seus meios de produção.

Um fato que chama a atenção é a postura do governo do Estado com relação à região Oeste do Estado do Paraná. Até meados da década de 1970 existia, tão somente, a preocupação em colonizar a região, fazer com que o espaço inabitado fosse povoado e, posteriormente, fizesse parte, de fato, do conjunto cultural e socioeconômico do Paraná. Esta afirmação é confirmada nos comentários de Lima (2004, p. 102) quando menciona que:

[...] Os governadores paranaenses anteriores a esse período haviam se empenhando em defender a policultura e a pequena propriedade, além de incentivar a vinda de gaúchos e catarinenses para o território do extremo oeste. Ao se aproximar da década de 1970, as preocupações se voltaram para a urbanização, a saúde, a educação, ou seja, para um processo de desenvolvimento baseado na industrialização. São governos que viveram o momento em que as relações com o Paraguai foram agitadas pela questão do aproveitamento das águas dos saltos de Sete Quedas.

Com o início das obras relativas à construção da Hidrelétrica Binacional de Itaipu, esta passa a ser a grande responsável pelas transformações socioespaciais e econômicas do Oeste paranaense. Nesse ínterim, observa-se como destaque a atração de população que trabalha direta ou indiretamente com o empreendimento e o desalojado pela formação do Lago de Itaipu.

Geografia Ensino \& Pesquisa, v. 18, n. 2 p. 7-24, maio/ago. 2014

Movimento populacional e transformações locais: os motores da Itaipu binacional

\section{Itaipu Binacional: reflexos na mobilidade populacional}

As alterações que a construção da Itaipu Binacional motivou no Oeste do Estado do Paraná, e em regiões do Paraguai e da Argentina, atualmente conhecidas como 'tríplice fronteira' são inegáveis.

Ocorreram transformações que implicaram em mudanças territoriais, pois como define SANTOS $(2011$, p.13) o território "[...] é o lugar em que desembocam todas as ações, todas as paixões, todos os poderes, todas as forças, todas as fraquezas, isto é, onde a história do homem plenamente se realiza a partir das manifestações da sua existência".

E o mesmo autor complementa este pensamento quando afirma que "o território é o fundamento do trabalho; o lugar da residência, das trocas materiais e espirituais e do exercício da vida”. (SANTOS, 2011, p. 14) 
Este território de trabalho, de residência de trocas comerciais, definido por Santos, passa a ser alterado, com a desapropriação de terras para a construção da barragem e a formação do lago, o incremento populacional, gerado pela oferta de emprego e consecutiva migração para Foz do Iguaçu provocando a especulação imobiliária e ampliando os problemas de configurações socioespaciais da cidade.

É a junção de elementos fixos e dos fluxos, que caracterizam a dinâmica territorial. Milton Santos define que:

\begin{abstract}
Os elementos fixos, fixados em cada lugar, permitem ações que modificam o próprio lugar, fluxos novos ou renovados que recriam as condições ambientais e as condições sociais, e redefinem cada lugar. Já os fluxos são um resultado direto ou indireto das ações e atravessam ou se instalam nos fixos, modificando a sua significação e seu valor, ao mesmo tempo que, também, se modificam. (SANTOS, 1996, p. 18).
\end{abstract}

Destacando este fluxo que se instala na região, temos o incremento populacional, que segundo o IPARDES (2008, p. 6), apresenta dados que comprovam que essa evolução não ocorreu somente no Brasil.

\begin{abstract}
Da mesma forma que nos anos 1970 o município de Foz do Iguaçu presenciou elevado crescimento populacional e do grau de urbanização, Ciudad del Este reproduz crescimento similar. Dados da Dirección General de Estadísticas, Encuestas y Censos (DGEEC), do Paraguai, apontam que, em 1972, a municipalidade tinha 26.485 habitantes, que se elevam para 62.328, em 1982, revelando também intenso ritmo de crescimento, que prossegue levando a uma população total, em 2005, de 260.594 habitantes. A municipalidade de Puerto Iguazú foi também impactada pelas obras, mesmo que a Argentina não tenha feito parte do acordo binacional. Sua população triplicou após 1970, quando detinha 3.001 habitantes, para 10.250, em 1980, e 31.515 habitantes em 2001, conforme dados do Instituto Nacional de Estadística y Censos (INDEC), da Argentina.
\end{abstract}

Em Foz do Iguaçu, existia uma preocupação especial com o crescimento populacional que este empreendimento motivaria. O IPARDES fez um estudo em 1977 e demonstrou uma estimativa da evolução da população local dividindo em três conjuntos distintos. A população denominada de 'normal', habitantes locais, a população instantânea, representada pelo turismo, e a população direta/indiretamente ligada à construção da hidrelétrica de Itaipu.

$\mathrm{Na}$ Tabela 3 pode-se constatar que a população envolvida na construção em comparação a população denominada de 'normal' é quase constante. Correspondendo por uma porcentagem média de $45 \%$, sendo maior de $50,32 \%$, no ano de 1976 , e a menor $16,76 \%$ no ano de 1976 . Projeta-se uma população total para Foz do Iguaçu de 112.594 habitantes no ano de 1985. Contudo, de acordo com o IBGE, no censo de 1980, a sua população já era de 136.231 habitantes, uma diferença de 23.637 pessoas, que foram atraídas para o município por fatores diversos, mas que não estavam na projeção inicial. Comprovando que a região era mais atrativa do que os estudos indicavam.

Como principal consequência deste crescimento populacional vertiginoso deu-se na área imobiliária, com um aumento dos preços para a aquisição de imóveis, pois:

[...] apartamentos de $120 \mathrm{~m} 2$ em média, com garagem para um carro, 3 quartos, 1 BWC, sala, cozinha e área de serviço, tem preço variando em torno de Cr $\$ 3.600,00$ o m2 em média, em Curitiba e São Paulo apartamentos, com conforto similar e mais acréscimo de área relativa a BWC privativo e dependências de empregados, custam em torno de $\mathrm{Cr} \$ 3.200,00 \mathrm{~m} 2$ e Cr $\$ 3.750,00 \mathrm{~m} 2$, respectivamente. É importante que se ponderem nessa comparação as diferenças de conforto e valorização permanente entre outas que se notam com relação à estrutura urbana de Foz do Iguaçu, e, Curitiba e São Paulo o que efetivamente, caracteriza Foz do Iguaçu como município em processo de especulação imobiliária intenso. (IPARDES, 1977, p. 231).

Geografia Ensino \& Pesquisa, v. 18, n. 2 p. 07-24, maio/ago. 2014.

Ostrovski, D. 
Tabela 3 - Decomposição da projeção da população urbana residente em "normal" e em função da construção de Itaipu.

\begin{tabular}{l|c|c|c|c|c}
\hline Anos & $\begin{array}{c}\text { População } \\
\text { "normal" }\end{array}$ & $\begin{array}{c}\text { População } \\
\text { Instantânea } \\
\text { (Turismo) }\end{array}$ & $\begin{array}{c}\text { População } \\
\text { Diretamente/Indiretamente } \\
\text { ligada à construção de } \\
\text { Itaipu }\end{array}$ & $\begin{array}{c}\text { \% } \\
\text { envolvida } \\
\text { na } \\
\text { construção } \\
\text { de Itaipu }\end{array}$ & Total \\
\hline 1970 & 18.605 & 2.084 & - & - & 20.689 \\
1971 & 19.982 & 2.560 & - & - & 22.542 \\
1972 & 21.462 & 3.130 & - & - & 24.542 \\
1973 & 23.050 & 3.650 & - & - & 26.700 \\
1974 & 24.757 & 3.840 & - & - & 28.597 \\
1975 & 26.589 & 4.400 & 6.240 & 16,76 & 37.229 \\
1976 & 28.558 & 5.050 & 34.050 & 50,32 & 67.658 \\
1977 & 30.672 & 5.780 & 36.635 & 50,14 & 73.059 \\
1978 & 32.942 & 6.550 & 37.475 & 48,68 & 76.967 \\
1979 & 35.381 & 7.350 & 38.515 & 47,40 & 81.246 \\
1980 & 38.000 & 8.200 & 39.360 & 46,00 & 85.560 \\
1981 & 40.862 & 9.500 & 40.350 & 44,70 & 90.262 \\
1982 & 43.941 & 9.800 & 41.390 & 43,53 & 95.081 \\
1983 & 47.249 & 10.600 & 43.830 & 43,10 & 101.679 \\
1984 & 50.811 & 11.400 & 44.970 & 41,95 & 107.181 \\
1985 & 54.639 & 12.150 & 45.805 & 40,68 & 112.594 \\
\hline
\end{tabular}

Fonte: IPARDES (1977, p. 208).

Constata-se que os preços praticados pelas imobiliárias eram semelhantes ou até superiores a capitais, no caso São Paulo e Curitiba, e isto também ocorria quando se tratava de aluguéis, comparando-se as mesmas cidades, os valores praticados em Foz do Iguaçu eram ainda maiores. $\mathrm{Na}$ cidade de Curitiba, por exemplo, o preço do aluguel por m2 era $50 \%$ menor que em Foz do Iguaçu e na cidade de São Paulo, aproximadamente 39 \%, como podemos constatar na Tabela 4.

Tabela 4 - Valores imobiliários.

\begin{tabular}{l|c|c}
\hline $\begin{array}{l}\text { Cidades } \\
\text { pesquisadas }\end{array}$ & Aluguel & Venda \\
\hline Foz do Iguaçu & Cr\$ 45,00 & Cr\$ 3.600,00 \\
Curitiba & Cr\$22.50 & Cr\$ 3.200,00 \\
São Paulo & Cr\$27,50 & $\operatorname{Cr} \$ 3.750,00$ \\
\hline
\end{tabular}

Fonte: IPARDES (1977, p. 231).

Geografia Ensino \& Pesquisa, v. 18, n. 2 p. $7-24$, maio/ago. 2014

Movimento populacional e transformações locais: os motores da Itaipu binacional
No decorrer dos anos, esta especulação imobiliária, provavelmente, persistiu. Dados censitários comprovam que Foz do Iguaçu manteve seu crescimento vertiginoso nos anos subsequentes. Conforme o IBGE, em 1970 o município possuía uma população de 33.966 habitantes, dez anos depois, isto é, em 1980, passou para 136.231. Onze anos mais tarde, com um crescimento menor, mas significativo, atingiu a marca de 190.123 habitantes. No censo de 2000, a população foziguaçuense era de 258.543 habitantes, e, em 2010, no último censo o número apontado foi de 250.918, representando uma retração de $2,9 \%$.

Nos demais municípios da região, as influências devidas à construção da Hidrelétrica de Itaipu foram mais sentidas ou percebidas quando o Lago se formou, isto porque a inundação de consideráveis parcelas de terras chegou a atingir mais que $25 \%$ do território, como foi o caso do município de Santa Helena e Foz do Iguaçu. Explica Mazzarollo, (2003. p. 31) que: 
$\mathrm{Na}$ época da construção da Itaipu eram oito os municípios diretamente afetados pela obra. Depois alguns distritos se desmembraram, e hoje são quinze os municípios. Em conjunto, eles perderam 13,90\% de seu território. Guaíra perdeu 10,30\%; Terra Roxa, 0,22\%; Marechal Cândido Rondon, 17,78\%; Santa Helena, 31,73; Matelândia, 0,45\%; Medianeira, 3,5\%, São Miguel do Iguaçu, 21,49\%; Foz do Iguaçu, 26,77\%.

Fato representativo, desse processo, foi à primeira desapropriação, que na informação de Ribeiro (2002 p. 23), ocorreu no distrito de Sede Alvorada do Iguaçu.

[...] Em primeiro lugar desapropriaram, na sede do distrito, as casas comerciais, os postos de combustíveis, as farmácias e, uma vez desapropriada com a infra-estrutura, os agricultores, que permaneceram, tinham que percorrer mais de 70 quilômetros para comprar combustíveis e outros produtos de que precisassem. Com isto, suas propriedades desvalorizavam. Todas as terras foram indenizadas por meio de contrato de compra e venda, pois ainda não havia sido promulgado o decreto de desapropriação por parte do Governo Federal.

Concomitantemente a esta desapropriação seguiram-se outras que totalizaram 8.519 propriedades, sendo 6.913 rurais e 1.606 urbanas, com uma área em hectares (ha) de 105.455,620 (Tabela 5).

Tabela 5 - Propriedades urbanas e rurais desapropriadas

\begin{tabular}{lcc}
\hline Localização & Número de propriedades & Área (ha) \\
\hline Urbanas & 1.606 & 484.789 \\
Rurais & 6.913 & $100.607,732$ \\
TOTAL & $\mathbf{8 . 6 1 9}$ & $\mathbf{1 0 5 . 4 5 5 , 6 2 0}$ \\
\hline
\end{tabular}

Fonte: Ribeiro (2002, p. 85).

As desapropriações, segundo Ribeiro (2002), foram estendidas por uma área de 1.350 $\mathrm{km} 2$, para a formação do Lago de Itaipu e das áreas de proteção ciliares. Deixou de ser produzido 100 mil toneladas de soja, cerca de 31 mil toneladas de trigo, quase 34 mil toneladas de milho, aproximadamente 1.500 toneladas de feijão, mais de 27 mil toneladas de mandioca, em torno de 1.700 toneladas de arroz e 24 toneladas de café.

Estas perdas significativas são fruto da inundação de áreas agricultáveis de alta fertilidade, que segundo Mazzarollo (2003. p. 32):

\footnotetext{
Em conjunto, os municípios atingidos perderam 13\% da área cultivada na época, $15,17 \%$ da quantidade produzida e $14,32 \%$ do valor da produção global. Foz do Iguaçu, o mais prejudicado, perdeu $33 \%$ da sua produção agrícola; São Miguel do Iguaçu teve a área cultivada reduzida em 25\%; Medianeira, 4,6\%; Guaíra, 10,7\%; e Marechal Candido Rondon, 17,8\%.
}

As informações contidas na Tabela 8 dão conta das perdas dos oito municípios existentes na época. Destaca-se em valores totais o caso de São Miguel do Iguaçu, que perdeu 26.253 hectares de terras cultiváveis, seguido de Santa Helena, que teve 25.992 hectares alagados, 25.075 hectares do município de Marechal Cândido Rondon e Foz do Iguaçu, que teve 23.570 hectares submersos pelas águas do Lago.

Geografia Ensino \& Pesquisa, v. 18, n.2 p. 07-24, maio/ago. 2014. 
Tabela 6 - Áreas dos municípios afetados pelo lago da Itaipu binacional

\begin{tabular}{lcccc}
\hline Município & Área total & Área afetada & $\%$ \\
\hline Guaíra & 53.666 & 5.530 & 10,30 \\
Terra Roxa & 82.925 & 183 & 0,22 \\
Marechal Cândido Rondon & 141.010 & 25.075 & 17,78 \\
Santa Helena & 81.916 & 25.992 & 31,73 \\
Matelândia & 108.697 & 492 & 0,45 \\
Medianeira & 122.772 & 4.237 & 3,45 \\
São Miguel do Iguaçu & 122.188 & 26.253 & 21,49 \\
Foz do Iguaçu & 88.220 & 111.332 & 13,90
\end{tabular}

Fonte: Ribeiro (2002. p. 28).

Ainda, conforme Mazzarollo (2003), o sistema viário foi muito comprometido, perdendo cerca de 900 quilômetros de estradas, correspondendo a 23,8\% do total, seja pela inundação ou inutilização de trechos. Em três casos específicos gerou isolamento de partes de territórios municipais, como em Santa Helena, que teve 45\% de seu território isolado, São Miguel do Iguaçu, com $12 \%$ e Foz do Iguaçu com 5\%. A reconexão demorou anos para ser reorganizada, provocando um grande êxodo populacional destes espaços.

Áreas urbanas também foram afetadas ou desapareceram sob as águas do Lago de Itaipu. É o caso, por exemplo, de Alvorada do Iguaçu, distrito de Foz do Iguaçu, que contava com 5.000 habitantes, Itacorá, distrito de São Miguel do Iguaçu, com cerca de 10.000 habitantes. Por problemas semelhantes passaram Santa Helena, que ficou cercada por três lados pelas águas do lago, interrompendo, momentaneamente, as ligações com os municípios vizinhos de Toledo e Marechal Cândido Rondon, sofrendo ainda, com a contaminação de suas águas em virtude da elevação do lençol freático, o que provocou o alagamento de poços e a contaminação das águas subterrâneas.

Na Tabela 7 tem-se a evolução populacional da região nas décadas de 1970, 1980, 1990, 2000 e 2010. Nela pode-se perceber o aumento ou o recuo populacional nestes municípios lindeiros. Destaca-se, principalmente, o período de formação do Lago, 1980 a 1990, e, consequente, o alagamento das parcelas de terras nos municípios.

Pode-se analisar através da Tabela 7 que todos os municípios, que já existiam antes da década de 1980, com exceção de Foz do Iguaçu, perderam população. Destaca-se que estas perdas, podem ser fruto de um conjunto de fatores, contudo, não somente a construção da Itaipu binacional e a necessidade da formação do lago, mas sim, que este foi um dos fatores mais importantes para o processo.

Com base nesses dados apresentados pode-se constatar que Foz do Iguaçu, teve seu maior aporte populacional entre as décadas de 1970 a 1990, aumentando 156.157 habitantes. Em contrapartida municípios como São Miguel do Iguaçu, por exemplo, teve uma perda populacional expressiva quando da formação do Lago de Itaipu. O município passou de 34.247 habitantes, no censo de 1980, para 24.721, onze anos depois, no censo de 1991, uma perda de 9.526 habitantes, cerca de $27,81 \%$ de seu contingente populacional.

Outro município que merece destaque especial é Santa Helena, que passou de 34.884 habitantes, em 1980, para 18.861 no censo de 1991, apontando uma perda de 16.023, correspondendo por $45,93 \%$ de sua população.

Movimento populacional e transformações locais: os motores da Itaipu binacional
Geografia Ensino \& Pesquisa, v. 18, n. 2 p. $7-24$, maio/ago. 2014 
Tabela 7 - Evolução populacional dos municípios lindeiros.

\begin{tabular}{lcccccccc}
\hline \multicolumn{1}{c}{ Município } & Fundação & 1970 & 1980 & 1991 & 2000 & 2010 \\
\hline Foz do Iguaçu -(PR) & 1914 & 33.966 & 136.231 & 190.123 & 258.543 & 256.088 \\
Santa Terezinha de & 1982 & - & - & 14.149 & 18.368 & 20.841 \\
Itaipu - (PR) & & & & & & \\
São Miguel do & 1961 & 25.747 & 34.247 & 24.721 & 24.432 & 25.769 \\
Iguaçu-(PR) & & & & & & \\
Itaipulândia-(PR) & 1992 & - & - & - & 6.836 & 9.026 \\
Medianeira-(PR) & 1960 & 31.142 & 49.361 & 38.665 & 37.827 & 41.817 \\
Missal-(PR) & 1983 & - & - & 10.372 & 10.433 & 10.474 \\
Santa Helena-(PR) & 1967 & 26.834 & 34.884 & 18.861 & 20.491 & 23.413 \\
Diamante D'Oeste- & 1989 & - & - & 9.253 & 4.878 & 5.027 \\
(PR) & & & & & & \\
São José das & 1989 & - & - & 5.596 & 4.102 & 3.830 \\
Palmeiras-(PR) & & & & & & \\
Marechal Cândido & 1960 & 43.776 & 56.210 & 49.430 & 41.007 & 46.819 \\
Rondon-(PR) & & & & & & \\
Mercedes-(PR) & 1993 & - & - & - & 4.608 & 5.046 \\
Pato Bragado-(PR) & 1993 & - & - & - & 4.093 & 4.822 \\
Entre Rios do Oeste- & 1993 & - & - & - & 3.328 & 3.926 \\
(PR) & & & & & & \\
Terra Roxa-(PR) & 1961 & 38.273 & 25.215 & 19.820 & 16.300 & 16.759 \\
Guaíra - (PR) & 1951 & 32.875 & 29.190 & 30.004 & 28.659 & 30.704 \\
Mundo Novo-(MS) & 1976 & - & 31.156 & 22.417 & 15.968 & 17.043 \\
\hline
\end{tabular}

Fonte: Organizado pelo autor com base em: IBGE - Censos demográficos 1970, 1980, 1991, 2000 e 2010.

Uma cidade que não registrou perda populacional significativa, mas sofreu por conta de sua perda de identidade foi Guaíra. Nesse sentido, comenta Mazzarollo (2003, p. 33) que:

Guaíra foi à cidade que mais sofreu em matéria de perdas em investimentos físicos. Perdeu a condição de polo turístico internacional em consequência da submersão de Sete Quedas e do Parque Nacional adjacente. Perdeu ainda boa parte de sua área urbana, o porto de transporte fluvial, estaleiros, olarias, um pequena hidrelétrica, uma reserva de camping, hotéis e restaurantes que atendiam turistas, um porto de extração de areia, consideráveis trechos de vias urbanas pavimentadas, boa parte do sistema de saneamento básico [...]

Concluindo é possível afirmar que esta região é de uma complexidade, quase indecifrável, pauta-se essa afirmação nas conclusões do IPARDES, redigidas em 1977, quando da conclusão de seu "Estudo dos efeitos econômicos e sociais da hidrelétrica de Itaipu sobre a região Oeste do Paraná". Infere o citado estudo que:

Por todas essas considerações, é preciso lembrar, finalmente, que pelas implicações geopolíticas envolvidas, toda a problemática depende da postura que venha a ser assumida diante deste problema concreto e real. Problema esse que, apesar de todas as dificuldades, é singular e original, não apenas por causa de Itaipu, mas sim pela inserção de Itaipu em uma região de crescimento vertiginoso, cujas potencialidades não foram ainda devidamente avaliadas, que apesar de todas as deficiências e dificuldades, vem revelando uma dinamicidade vigorosa. É desta inserção que se caracteriza um problema concreto de desenvolvimento regional-urbano, oportunidade única que se oferece como desafio, constituindo-se em um teste fatalmente rico em experiência, sobre a viabilidade real de integração dos objetos nacionais/estaduais/regionais/locais. (IPARDES, 1997, p. 282).

Geografia Ensino \& Pesquisa, v. 18, n. 2 p. 07-24, maio/ago. 2014.

Ostrovski, D. 
Três décadas e meio depois o IPARDES, mantém na publicação editada em 2008 sob o título de "Os vários Paranás", o destaque de região promissora, indicando-a como responsável por um ambiente dinâmico, complexo, metamorfoseado e que consegue com suas relações manter uma rede densa de cidades. Esta região pode então ser considerada a:

[...] "Última fronteira" de ocupação e expansão da exploração agropecuária, esta porção do Estado reúne indicadores econômicos e institucionais que a situam entre os três espaços de maior relevância do Estado, sendo uma das regiões onde a complementaridade das atividades produtivas resulta em uma agroindústria dinâmica com importantes impactos regionais, capazes de provocar rearranjos na estrutura fundiária local e na configuração populacional, consolidando uma densa rede de cidades. (IPARDES, 2008, p.09)

Portanto, muitas destas transformações não teriam acontecido caso o empreendimento binacional não tivesse se concretizado, no entanto, devido sua concretização pode-se afirmar que a Itaipu Binacional influenciou e continuará a influenciar a região Oeste do Estado do Paraná.

\section{Considerações finais}

Observa-se claramente a interferência do poder público na busca de ocupação do Oeste Paranaense. Foram iniciativas que ocasionaram a ocupação regular, com o modelo obrageiro de exploração do espaço, e posteriormente a ocupação organizada pelas grandes colonizadoras, com venda de lotes de terras a imigrantes provenientes, principalmente, do Estado do Rio Grande do Sul. No entanto, assim não se pode negligenciar a importância da ocupação espontânea, oriunda de poceiros e grileiros que fizeram parte da ocupação dessas áreas, permitindo que a frente de ocupação desenvolvesse uma atividade econômica de subsistência, voltada para o mercado regional.

Tal modelo perdura até a implantação do projeto da construção da hidrelétrica binacional de Itaipu, em parceria com o Paraguai. Os desdobramentos oriundos desta obra passam a alterar significativamente o espaço territorial do Oeste do Estado do Paraná.

Sua construção motivou a migração de um contingente populacional significativo. No primeiro momento atraiu para este espaço, pela oferta de emprego direto e indireto, o grupo de trabalhadores conhecidos como barrageiros, (operários especializados na construção de hidrelétricas), e posteriormente, com o fechamento das comportas e a formação do lago, obrigou a saída das pessoas que habitavam as terras que foram inundadas.

Essa mobilidade populacional, de dois fluxos, altera significativamente a configuração populacional do Oeste do Estado do Paraná. A cidade de Foz do Iguaçu tem sua população, quase que do dia para a noite, triplicada, ao passo que cidades lindeiras ao lago, testemunham sua população diminuir, seu território ser fragmentado e inundado. Fluxos são interrompidos, padrões de vida são alterados, modos de vida e ocupação são eliminados.

Destaca-se que com o passar do tempo estas alterações são equilibradas e a 'vida cotidiana' retornou ao Oeste do Estado. Contudo, este empreendimento estatal continua a influenciar o espaço no seu entorno, com medidas ambientais, desenvolvidas através do programa Cultivando

Geografia Ensino \& Pesquisa, v. 18, n. 2 p. $7-24$, maio/ago. 2014

Movimento populacional e transformações locais: os motores da Itaipu binacional Água Boa, a distribuição de Royalties, o auxilio a instalação de universidades como a UNILA Universidade da Integração Latina Americana, a criação do PTI - Parque Tecnológico Itaipu, a instalação em seus prédios do polo de educação a distância da cidade de Foz do Iguaçu, bem como a geração de inúmeros empregos diretos e indiretos. Desta forma, pode-se afirmar que a Itapu Binacional influenciou e influenciará o seu espaço territorial, nas mais diversas frentes, sendo o grande motor da mobilidade populacional. 


\section{Referências}

BERNADES, Lysia Maria Cavalcati. O problema das “frentes pioneiras” no estado do Paraná. Revista Brasileira de Geografia. Rio de Janeiro, a. XV, n, 3, p. 335-84, jul/set., 1953.

BERNADES, Nilo. Expansão do povoamento no estado do Paraná. Revista Brasileira de Geografia. Rio de Janeiro, a. 14, n. 4, p. 427-56, out/dez., 1952.

GREGORY, Valdir. Os eurobrasileiros e o espaço colonial: a dinâmica da colonização do oeste do Paraná nas décadas de 1940 a 1970. Tese (Doutorado). Niterói: Universidade Federal Fluminense, 1997.

GREGORY, Valdir. Os eurobrasileiros e o espaço colonial: a dinâmica da colonização do oeste do Paraná (1940 a 1970). Cascavel: Edunioeste, 2002.

GUILHERME VELHO, Octavio. Capitalismo autoritário e campesinato. São Paulo, Difel, 1979.

HAESBAERT, Rogério. O mito da desterritorialização: do fim dos territórios à multiterritorialidade. Rio de Janeiro: Bertrand Brasil, 2004.

IPARDES. Instituto Paranaense de Desenvolvimento Econômico e Social. Os vários Paranás: oeste paranaense, o $3^{\circ}$ espaço relevante, especificidades e variedades. Curitiba; IPARDES, 2008.

IPARDES. Instituto Paranaense de Desenvolvimento Econômico e Social. Estudo dos efeitos econômicos e sociais da hidrelétrica de Itaipu sobre a região oeste do Paraná. Curitiba, 1977. Disponível em: <http://www.ipardes.gov.br/>. Acesso em: 23 abr. de 2012.

IPARDES. Instituto Paranaense de Desenvolvimento Econômico e Social. Impacto ambiental de Itaipu. Curitiba, v. 1 e 2 1981. Disponível em: <http://www.ipardes. gov.br/>. Acesso em: 23 abr. 2012.

KONZEN, Otto Guilherme; ZAPPAROLI, Irene Domenes. Estrutura agrária e capitalização da agricultura no Paraná. Economia Social Rural. Brasília, n. 28, p. 155-73, out./dez. 1990.

LIMA, Ivone Teresinha Carletto. Itaipu: as faces de um mega projeto de desenvolvimento (1930 1984). Marechal Cândido Rondon: Germânica, 2006.

MAZZAROLLO, Juvêncio. A taipa da injustiça: esbanjamento econômico, drama social e holocausto ecológico em Itaipu. 2 ed. São Paulo: Loyola, 2003.

NICHOLLS, William H. A fronteira agrícola na história recente do Brasil: o estado do Paraná, 1920-65. Revista Paranaense de Desenvolvimento. Curitiba: Fundação Getúlio Vargas, n. 26, 1971.

RAFFESTIN, Claude. Por uma Geografia do poder. São Paulo: Ática, 1993.

REGO, Rubem Murilo Leão. A questão agrária e o momento atual. ABRA. Boletim da Reforma Agrária, Campinas, 1980.

REGO, Rubem Murilo Leão. Tensões sociais na frente de expansão: a luta pela terra no Sudoeste do Paraná - 1940/1970. Boletim da Universidade Federal do Paraná. Curitiba: UFPR, 1975, 1975.

RIBEIRO, Maria de Fátima Bento. Memórias do concreto: vozes na construção de Itaipu. Cascavel: Edunioeste: 2002.

SANTOS, Milton. O dinheiro e o território. In: Território, territórios: ensaios sobre o ordenamento territorial. 3 ed. Rio de Janeiro: Lamparina, 2011.

SANTOS, Milton. A natureza do Espaço: técnica e tempo, razão e emoção. São Paulo: Hucitec, 1996.

Geografia Ensino \& Pesquisa, v. 18, n.2 p. $07-24$, maio/ago. 2014 
agrário no Paraná. Boletim de Geografia. Maringá: UEM, a. 10, n. 1, 1992, 1992.

WACHOWICZ, Ruy Christovam. Obrageiros, mensus e colonos: história do oeste paranaense. Curitiba: Vicentina, 1982.

WACHOWICZ, Ruy Christovam. Paraná, sudoeste: ocupação e colonização. Curitiba: Lítero-Técnica, 1985.

WESTPHALEN, Cecília Maria.; MACHADO, Brasil Pinheiro.; BALHANA, Altiva Pilatti. Nota prévia ao estudo da ocupação da terra no Paraná moderno. Boletim da Universidade Federal do Paraná. Departamento de História. Curitiba: UFPR, n. 7. p. 3-51, 1968.

\section{Correspondência:}

\section{Dalésio Ostrovski}

E-mail: dalesio@utfpr.edu.br

Recebido em 18 de fevereiro de 2014.

Revisado pelo autor em 29 de maio de 2014.

Aceito para publicação em 09 de julho de 2014. 